\title{
Evaluating the longitudinal effectiveness of preventive measures against COVID-19 and seroprevalence of IgG antibodies to SARS-CoV-2 in cancer outpatients and healthcare workers
}

\author{
Dominic Fong (D) - Katja Olga San Nicolò · Monika Alber · Manfred Mitterer \\ Received: 8 September 2020 / Accepted: 30 December 2020 / Published online: 27 January 2021 \\ (C) Springer-Verlag GmbH, AT part of Springer Nature 2021
}

\begin{abstract}
Summary
Background It has been assumed that cancer patients, especially those undergoing chemotherapy, are at increased risk for infection and severe illness from severe acute respiratory syndrome coronavirus 2 (SARSCoV-2) compared to the general population. After the first alert message from the local healthcare service, a series of drastic measures were taken at our outpatient clinic to contain the spread of coronavirus disease 2019 (COVID-19).

Methods In this retrospective study, all consecutive cancer outpatients completed a baseline SARS-CoV-2 test via real-time polymerase chain reaction (RT-PCR) from 15 March to 26 May 2020. In the later phase, after the peak of the pandemic, patients as well as healthcare workers were tested for anti-SARS-CoV-2 IgG antibodies.

Results Between 15 March and 26 May 2020, 0.78\% $(N=5 / 640)$ cancer patients tested positive for SARSCoV-2 by RT-PCR. Between 22 June and 17 July 2020, anti-SARS-CoV-2 IgG antibodies were detected in 2 out of $250(0.8 \%)$ cancer patients and 2 out of 36 $(5.5 \%)$ healthcare workers. In only 1 out of 4 cancer patients with confirmed COVID-19 infection, could SARS-CoV-2 antibodies be detected.

Conclusion Our findings suggest that the majority of our patients and healthcare workers had not been infected with SARS-CoV-2 and rapidly implemented measures were effective. Maintenance of preventive
\end{abstract}

\footnotetext{
Data availability The datasets used and analyzed during the current study are available from the corresponding author on reasonable request.

Dr. D. Fong $(\bowtie) \cdot$ K. O. San Nicolò · M. Alber $\cdot$ M. Mitterer Department of Oncology and Hematology, Franz Tappeiner Hospital, Rossinistraße 5, 39012 Merano, Italy dominic.fong@i-med.ac.at; dominic.fong@sabes.it
}

measures should be continued until vaccines or specific treatments are available.

Keywords Coronavirus - COVID pandemic . Chemotherapy · Oncological patients · Prevalence

\section{Abbreviations}

COVID-19 Coronavirus disease 2019

RT-PCR Real time polymerase chain reaction

SARS-CoV-2 Severe acute respiratory syndrome coronavirus 2

\section{Introduction}

The coronavirus disease 2019 (COVID-19), caused by severe acute respiratory syndrome coronavirus 2 (SARS-CoV-2) is characterized by rapid human-tohuman transmission and a wide range of clinical manifestations from mild, moderate, to severe and rapidly progressive or fulminant disease [1]. On 11 March 2020, the World Health Organization (WHO) declared COVID-19 a global pandemic, which has created an evolving global public health and economic crisis [2]. During the early stage of the pandemic, data from China and Italy reported a higher incidence and risk of severe events in SARS-CoV-2 positive cancer patients [3-6]. As a consequence, in the absence of a vaccine or adequate treatment of COVID-19, introduction of strict infection control procedures and policies has been recommended by various oncological societies [7-10]; however, follow-up data on the efficacy of such interventions and the maintenance of infection control measures in oncological patients are limited.

Italy was one of the heavily affected countries in Europe with more than 240,000 confirmed cases and 35,000 deaths as of 27 July 2020 [11]. The first wave of SARS-CoV-2 infections outside the northern Lom- 
bardy region, which was the epicenter of the novel coronavirus disease in Italy, has abated because of aggressive nonpharmaceutical interventions; however, given the steady increases in daily case counts in different countries by lifting restrictions prematurely, data about the long-term efficacy of measures may help to protect particularly vulnerable subjects such as cancer patients.

Furthermore, true prevalence of COVID-19 in cancer patients has still not been assessed as many patients may have mild or asymptomatic infections and will not be detected by RT-PCR testing due to limited capacity and strict criteria. Therefore, serologic assays to detect specific antibodies against SARS-CoV-2 can better evaluate the number of infections and identify subjects who may still contribute to ongoing virus transmission. Results from seroprevalence studies in the general population suggest that most persons remained uninfected during the first epidemic wave, far away from reaching herd immunity [12, 13]. In the present study, we report the first follow-up results of the efficacy of longitudinal preventive measures as well as the seroprevalence of anti-SARS-CoV-2 IgG antibodies in cancer patients on active treatment from a tertiary care hospital in northern Italy.

\section{Patients and methods}

All consecutive patients treated at the outpatient department of the "Franz Tappeiner" Hospital Merano, from 15 March to 26 May 2020 were included in this retrospective study. Specific infection prevention and control measures were maintained by the hospital as well as our clinic as described previously [14]. Universal baseline testing for SARS-CoV-2 RNA was performed using a real-time polymerase chain reaction (RT-PCR) on respiratory samples obtained from nasopharyngeal swabs of patients and all healthcare workers. Furthermore, from 22 June to 17 July 2020 a total of 250 consecutive cancer patients who underwent SARS-CoV-2 PCR baseline testing as well as the entire healthcare team were tested for the presence of IgG antibodies against SARS-CoV-2 in venous blood samples. Serologic testing was performed using the commercially available Abbott Architect SARSCoV-2 IgG assay to detect immunoglobulin class $G$ (IgG) antibodies to the nucleocapsid protein of SARSCoV-2 (Abbott Diagnostics, Chicago, Ill, USA). Sensitivity and specificity for the Abbott Architect SARSCoV-2 IgG assay were found to be $100 \%$ and $99.6 \%$, respectively [15]. The study was approved by the local ethics committee of the "Südtiroler Sanitätsbetrieb" (protocol number 35-2020).

\section{Results}

From 15 March to 26 May 2020, a total number of 865 consecutive patients treated at our hemato-oncological outpatient department were included for univer- sal baseline SARS-CoV-2 testing in this retrospective study. In total, 2966 patient visits were carried out and 1096 treatments have been intravenously applied. Patients were categorized into two groups based on the history of a cancer diagnosis. Median age for male patients with chronic nonmalignant disorders $(N=132)$ was 60 years (range 21-93 years) and for female $(N=93)$ patients 55 years (range 22-92 years). Because this follow-up study predominantly focussed on cancer patients, all 225 patients treated for chronic nonmalignant disorders (inflammatory bowel disease, $N=42$; monoclonal gammopathy of undetermined significance, $N=40$; multiple sclerosis, $N=39$; iron overload disorders, $N=33$; secondary polycythemia, $N=24$; idiopathic thrombocytopenic purpura, $N=13$; iron deficiency anemia, $N=12$; hypogammaglobulinemia, $N=11$; others, $N=11$; all tested negative for COVID-19 by SARS-CoV-2 RT-PCR) were excluded from further analyses.

Demographic and clinical characteristics of cancer patients tested for SARS-CoV-2 are summarized in Table 1. As of the data cut-off on 26 May 2020, a total of 348 oncology patients with a median age of 69 years (range 26-89 years) and 292 hematology patients (median age 71 years, range 18-96 years) were screened for SARS-CoV-2 by PCR. Altogether, 282/348 $(81.1 \%)$ patients received active anticancer treatment for oncological and 158/292 (54.1\%) patients for malignant hematological diseases, respectively. Among those patients not receiving active treatment, 54/348 (15.5\%) oncological patients were cancer survivors in routine follow-up, whereas $3.4 \%(12 / 348)$ of the patients received best supportive care (BSC). In the subgroup of patients with hematological malignancies, routine follow-up was performed in 99/292 (33.9\%) of patients, whereas $12.0 \%(35 / 292)$ of the patients were treated with BSC. Within the observation period $5 / 640(0.78 \%)$ of our cancer patients tested positive for SARS-CoV-2 by RT-PCR. Briefly, all but one patient acquired infection outside the hospital. The majority ( 4 out of $5,80 \%$ ) of patients were asymptomatic and outcomes were favorable with only one death due to progression of metastatic disease. A detailed summary of COVID-19 positive patients is summarized in Table 2.

As of the data cut-off on 17 July 2020, a total of 250 consecutive cancer patients were additionally tested for seroprevalence by measuring anti-SARSCoV-2 IgG antibodies. Among the 250 cancer patients who underwent SARS-CoV-2 PCR and serology, results were concordant in $98.4 \%$ of cases (245 patients tested negative and 1 patient tested positive for both approaches) and discordant in $4(1.6 \%)$ cases. In 3 cases, SARS-CoV-2 RNA was detected in seronegative patients whereas 1 seropositive patient had repeat negative SARS-CoV-2 PCR test. Interestingly, 2 of 3 seronegative SARS-CoV-2 infected patients were treated with rituximab-based chemoimmunotherapy. 
Table 1 Demographic data and baseline characteristics of all patients tested for SARS-CoV-2 by RT-PCR

\begin{tabular}{|c|c|c|}
\hline Parameters & $\begin{array}{l}\text { Number of } \\
\text { patients (\%) }\end{array}$ & $\begin{array}{l}\text { Median age } \\
\text { years (range) }\end{array}$ \\
\hline Total cohort & $865(100 \%)$ & $68(18-96)$ \\
\hline $\begin{array}{l}\text { Patients with malignant } \\
\text { disease }\end{array}$ & $640(73.9 \%)$ & $70(18-96)$ \\
\hline $\begin{array}{l}\text { Patients with chronic nonmalig- } \\
\text { nant disease }\end{array}$ & $225(26.1 \%)$ & $58(21-93)$ \\
\hline \multicolumn{3}{|c|}{ Patients with malignant disorders } \\
\hline $\begin{array}{l}\text { Patients with oncological dis- } \\
\text { ease }\end{array}$ & $348(54.4 \%)$ & $69(26-89)$ \\
\hline $\begin{array}{l}\text { Patients with malignant } \\
\text { hematologic disease }\end{array}$ & $292(45.6 \%)$ & $71(18-96)$ \\
\hline \multicolumn{3}{|l|}{ Gender } \\
\hline Male & $303(47.3 \%)$ & $69(18-91)$ \\
\hline Female & $337(52.7 \%)$ & $72(19-96)$ \\
\hline Disease & COVID- & COVID+ \\
\hline Solid tumors $(N=348)$ & $345(99.1 \%)$ & $3(0.9 \%)$ \\
\hline Breast cancer & $94(27.1 \%)$ & - \\
\hline Lung cancer & $48(13.8 \%)$ & $1(0.3 \%)$ \\
\hline Prostate cancer & $41(11.8 \%)$ & - \\
\hline Colorectal cancer & $38(10.9 \%)$ & - \\
\hline Ovarian cancer & $24(6.9 \%)$ & - \\
\hline Renal cancer & $17(4.8 \%)$ & - \\
\hline Melanoma & $13(3.7 \%)$ & - \\
\hline Gastric cancer & $11(3.2 \%)$ & - \\
\hline Cervical cancer & $7(2.0 \%)$ & - \\
\hline Pancreatic cancer & $6(1.7 \%)$ & $1(0.3 \%)$ \\
\hline Bladder cancer & $6(1.7 \%)$ & - \\
\hline Neuroendocrine tumors & $6(1.7 \%)$ & - \\
\hline Esophageal cancer & $5(1.4 \%)$ & - \\
\hline Sarcoma & $5(1.4 \%)$ & - \\
\hline Anal carcinoma & $5(1.4 \%)$ & - \\
\hline Glioblastoma & $4(1.1 \%)$ & - \\
\hline Appendix cancer & $3(0.9 \%)$ & - \\
\hline $\begin{array}{l}\text { Nonseminomatous germ cell } \\
\text { tumor }\end{array}$ & $2(0.6 \%)$ & - \\
\hline Hepatocellular carcinoma & $2(0.6 \%)$ & - \\
\hline Cancer of unknown primary & $2(0.6 \%)$ & - \\
\hline Gastrointestinal stromal tumor & $2(0.6 \%)$ & - \\
\hline Biliary tract cancer & $1(0.3 \%)$ & $1(0.3 \%)$ \\
\hline Mesothelioma & $1(0.3 \%)$ & - \\
\hline Thymic carcinoma & $1(0.3 \%)$ & - \\
\hline Hypopharyngeal cancer & $1(0.3 \%)$ & - \\
\hline $\begin{array}{l}\text { Hematologic malignan- } \\
\text { cies }(N=292)\end{array}$ & $290(99.3 \%)$ & $2(0.7 \%)$ \\
\hline $\begin{array}{l}\text { Chronic myeloproliferative } \\
\text { disease }\end{array}$ & $90(30.8 \%)$ & - \\
\hline Indolent lymphoma & $82(28.1 \%)$ & $2(0.7 \%)$ \\
\hline Multiple myeloma & $43(14.8 \%)$ & - \\
\hline Myelodysplastic syndrome & $36(12.3 \%)$ & - \\
\hline Aggressive lymphoma & $27(9.2 \%)$ & - \\
\hline Hodgkin disease & $9(3.1 \%)$ & - \\
\hline Acute myeloid leukemia & $2(0.7 \%)$ & - \\
\hline Light-chain amyloidosis & $1(0.3 \%)$ & - \\
\hline
\end{tabular}

Table 1 (Continued)

\begin{tabular}{|l|l|l|}
\hline Parameters & $\begin{array}{l}\text { Number of } \\
\text { patients (\%) }\end{array}$ & $\begin{array}{l}\text { Median age } \\
\text { years (range) }\end{array}$ \\
\hline Oncology treatment & $\begin{array}{l}\text { Solid tumors } \\
\text { (N=348) }\end{array}$ & $\begin{array}{l}\text { Hematologic ma- } \\
\text { lignancies (N= 292) }\end{array}$ \\
\hline Conventional chemotherapy & $105(30.2 \%)$ & $82(28.1 \%)$ \\
\hline Immunotherapy & $53(15.2 \%)$ & $15(5.1 \%)$ \\
\hline Chemoimmunotherapy & $31(8.9 \%)$ & $23(7.9 \%)$ \\
\hline Targeted therapy & $58(16.7 \%)$ & $38(13.1 \%)$ \\
\hline Antihormone therapy & $34(9.8 \%)$ & - \\
\hline Follow-up & $54(15.5 \%)$ & $99(33.9 \%)$ \\
\hline Best supportive care & $12(3.4 \%)$ & $35(12.0 \%)$ \\
\hline Radiotherapy & $1(0.3 \%)$ & - \\
\hline $\begin{array}{l}\text { SARS-CoV-2 severe acute respiratory syndrome coronavirus 2, RT-PCR real- } \\
\text { time polymerase chain reaction, COVID-19 coronavirus disease 2019 }\end{array}$
\end{tabular}

Furthermore, all healthcare workers (9 physicians, 23 nurses, 2 technicians, 2 secretaries) from our department have been tested for SARS-CoV-2 by PCR as well as IgG antibodies. None of them was positive on repeat screening (days 0,7 and 14) tests or further suspicion for infection by RT-PCR. In the later phase, when serologic tests became available, two healthcare professionals were SARS-CoV-2 IgG positive. Cumulative prevalence (antibody test and previous RT-PCR) was $2.4 \%(6 / 250)$ in tested cancer patients, and $5.5 \%$ $(2 / 36)$ in healthcare workers.

\section{Discussion}

Data about the ability to deliver appropriate cancer treatment during the COVID-19 pandemic are still limited. In addition, studies overall provide conflicting infection rates and are partially based on a small number of cancer patients [6, 16, 17]. We recently reported our specific precautions for cancer patients and healthcare workers to prevent spread during early phase of COVID-19 endemic as well as initial observations of infections at our outpatient clinic [14]. Measures and infection control policies, which were quickly implemented for patients and staff, were kept in place to ensure the continuum of cancer care.

The present study underlines the following observations: after the epidemic has reached its peak, continued consecutive baseline testing by RT-PCR of all our patients revealed a SARS-CoV-2 prevalence of $0.57 \%$ ( 5 of 865 ) in the entire cohort and $0.78 \%$ $(5 / 640)$ in cancer patients. All cases were diagnosed within the first 2 weeks over a 10 -week test period. No patient with chronic nonmalignant disorder became infected with SARS-CoV-2 and all healthcare workers from our outpatient clinic were tested SARS-CoV-2 negative by RT-PCR.

Test methods targeting SARS-CoV-2 viral RNA are currently the gold standard for the diagnosis of COVID-19; however, false negative rates due to poor specimen quality or timing of collection remain a key question and mild or asymptomatic subjects 
Table 2 Clinical data of the subgroup of cancer patients tested positive for SARS-CoV-2 by RT-PCR and/or anti-SARS-CoV-2 IgG antibodies

\begin{tabular}{|c|c|c|c|c|c|c|}
\hline \multicolumn{7}{|c|}{ Subgroup of COVID-19 positive cancer patients } \\
\hline & Case \#1 & Case \#2 & Case \#3 & Case \#4 & Case \#5 & Case \#6 \\
\hline Age/gender & 71 years, female & 73 years, female & 69 years, female & 63 years, male & 76 years, male & 72 years, female \\
\hline Diagnosis & Pancreatic cancer & $\begin{array}{l}\text { Biliary tract can- } \\
\text { cer }\end{array}$ & $\begin{array}{l}\text { Mantle cell lym- } \\
\text { phoma }\end{array}$ & Chronic lymphocytic leukemia & $\begin{array}{l}\text { Non-small cell } \\
\text { lung cancer }\end{array}$ & $\begin{array}{l}\text { Myelodysplastic } \\
\text { syndrome }\end{array}$ \\
\hline Current treatment & Capecitabine & $\begin{array}{l}\text { Cisplatin + gem- } \\
\text { citabine }\end{array}$ & $\begin{array}{l}\text { Bendamustine + } \\
\text { rituximab }\end{array}$ & $\begin{array}{l}\text { Fludarabine + cyclophos- } \\
\text { phamide + rituximab }\end{array}$ & Atezolizumab & Lenalidomide \\
\hline Comorbidities & Diabetes, hypertension & Hypertension & $\begin{array}{l}\text { Hypertension, } \\
\text { obesity }\end{array}$ & Chronic renal failure & $\begin{array}{l}\text { Hypertension, } \\
\text { stroke }\end{array}$ & Hypothyroidism \\
\hline Smoker & No & No & No & Yes & Yes & No \\
\hline $\begin{array}{l}\text { COVID-19 infection } \\
\text { source }\end{array}$ & Nosocomial & Nursing home & $\begin{array}{l}\text { Community ac- } \\
\text { quired }\end{array}$ & Community acquired & Nursing home & $\begin{array}{l}\text { Community } \\
\text { acquired }\end{array}$ \\
\hline SARS-CoV-2 RT-PCR & Positive & Positive & Positive & Positive & Positive & Negative \\
\hline $\begin{array}{l}\text { SARS-CoV-2 IgG } \\
\text { antibody test }\end{array}$ & n.a. & Positive & Negative & Negative & Negative & Positive \\
\hline COVID-19 symptoms & Asymptomatic & Asymptomatic & Fever & Asymptomatic & Asymptomatic & Asymptomatic \\
\hline COVID-19 outcome & $\begin{array}{l}\text { Death due to tumor } \\
\text { progression }\end{array}$ & Resolved & Resolved & Resolved & Resolved & Resolved \\
\hline
\end{tabular}

might not be tested and consequently not diagnosed. To date, the best information on infection rates of SARS-CoV-2 among cancer patients comes from two larger case series from China and Italy using RT-PCR tests $[6,18]$. Yu et al. estimated the infection rate of SARS-CoV-2 in patients with cancer at $0.79 \%$ (12 of 1524), whereas the second study from Italy reported an infection rate of $0.71 \%$ among 1257 patients on active anticancer treatment after adoption of practical health recommendations in their hospital.

However, obtained results from RT-PCR testing for viral RNA in nasopharyngeal swabs can only detect active infection and not exposure. Detection of antibodies to SARS-CoV-2 may indicates an infection at some point and thus, serologic assays have the capacity to support PCR testing and better estimate the true number of infections. So far, data on the seroprevalence of anti-SARS-CoV-2 antibodies in cancer patients are scarce. Only recently, Liu et al. reported first results on the prevalence of IgG antibodies against SARS-CoV-2 in 40 cancer patients with COVID-19 [19]. Prevalence of IgG antibodies to SARS-CoV-2 in cancer patients with COVID-19 was significantly lower $(72.5 \%)$ compared to patients without cancer $(90.3 \% ; p<0.001)$; however, no information about the different types of cancer or treatment was available.

In the present study, seroprevalence of anti-SARSCoV-2 IgG antibodies was $0.8 \%$ (2 of 250) in cancer patients and $5.5 \%$ ( 2 of 36 ) in staff members of our outpatient clinic. Cumulative prevalence (antibody test and previous RT-PCR) was $2.4 \%(6 / 250)$ in tested cancer patients, and $5.5 \%(2 / 36)$ in healthcare workers. More than two thirds $(68.7 \%)$ of our patients were currently on active anticancer treatment during the period of observation. Out of six COVID19 positive cancer patients five $(83.3 \%)$ were asymp- tomatic and overall outcomes were good with only one death due to progressive metastatic cancer. SARSCoV-2 transmission occurred in the majority of patients outside the hospital. Of note, both of our patients who have been treated with rituximab-based chemoimmunotherapy failed to seroconvert to SARSCoV-2. Similar results were reported in patients with autoimmune disease who have undergone treatment with the anti-CD20 monoclonal antibodies rituximab and ocrelizumab [20-22]. Therefore, serology testing for SARS-CoV-2 might not be a reliable tool to detect COVID-19 infection in cancer patients treated with anti-CD20 therapy.

In addition, we found $79(3.0 \%)$ confirmed symptomatic COVID-19 infections tested by RT-PCR among a total of 2612 hospital workers and a seroprevalence of IgG antibodies against SARS-CoV-2 in 50 of 1657 $(3.0 \%)$ tested persons at the hospital in Merano over the same observation period (data not shown). These findings are in line with other studies of healthcare workers from Central Italy and Wuhan, the first epicenter of the coronavirus crisis [23, 24].

Major limitations of our study include the retrospective study design within a single institution and small sample size of SARS-CoV-2 infected cancer patients; however, considering a recent rise in COVID-19 cases in many countries, additional data on the seroprevalence of cancer patients and healthcare workers can provide important information to face a future wave. Furthermore, particularly those patients with chronic disease and repeated hospital visits may be worried about the higher risk of SARS-CoV-2 infection and known immunity within healthcare facilities to the virus might help to reduce fears.

In conclusion, our findings suggest that the majority of our patients and healthcare workers had not 
been infected with SARS-CoV-2 and implemented measures were effective over a long period. Maintenance of preventive measures should be continued until vaccines or specific treatments are available. In addition, we could demonstrate that repeated hospital visits for active anticancer treatment might not increase the risk for SARS-CoV-2 infection, if powerful prevention and control policies are implemented rapidly by both patients and healthcare providers. Furthermore, continuous COVID-19 patient education and communication may further reduce the risk of infection.

Acknowledgements The authors thank all the staff of the Outpatient Clinic for their efforts and dedication to the study and acknowledge all the participants whose contributions made this study possible.

Funding This work was supported by the budget of the Südtiroler Sanitätsbetrieb.

Author Contribution D.F. and M.M. conceived and designed the study. K.O.S.N, M.A., M.M. contributed to acquisition of data and M.M. provided statistical support. D.F. wrote the manuscript. All authors analyzed data and reviewed the manuscript.

\section{Compliance with ethical guidelines}

Conflict of interest D. Fong, K.O. San Nicolò, M. Alber, and M. Mitterer declare that they have no competing interests.

Ethical standards All procedures performed in studies involving human participants or on human tissue were in accordance with the ethical standards of the institutional and/or national research committee and with the 1975 Helsinki declaration and its later amendments or comparable ethical standards. The study was approved by the local ethics committee of the "Südtiroler Sanitätsbetrieb" (protocol number 35-2020). All subjects provided written informed consent.

\section{References}

1. Guan WJ, Ni ZY, Hu Y, et al. Clinical characteristics of coronavirus disease 2019 in China. N Engl J Med. 2020;382(18):1708-20.

2. Hartley DM, Perencevich EN. Public health interventions for COVID-19: emerging evidence and implications for an evolving public health crisis. JAMA. 2020; https://doi.org/ 10.1001/jama.2020.5910.

3. Liang W, Guan W, Chen R, et al. Cancer patients in SARSCoV-2 infection: a nationwide analysis in China. Lancet Oncol. 2020;21(3):335-7.

4. Dai M, Liu D, Liu M, et al. Patients with cancer appear more vulnerable to SARS-coV-2: a multicenter study during the COVID-19 outbreak. Cancer Discov. 2020;10(6):783-91.

5. Onder G, Rezza G, Brusaferro S. Case-fatality rate and characteristics of patients dying in relation to COVID-19 in Italy. JAMA. 2020; https://doi.org/10.1001/jama.2020. 4683.

6. Yu J, OuyangW, Chua MLK, XieC. SARS-CoV-2 transmission in patients with cancer at a tertiary care hospital in Wuhan, China. JAMA Oncol. 2020;6(7):1108-10.

7. Peng L, Zagorac S, Stebbing J. Managing patients with cancer in the COVID-19 era. Eur J Cancer. 2020;132:5-7.
8. ESMO. CancerpatientmanagementduringCOVID-19 pandemic. 2020. https://www.esmo.org/guidelines/cancerpatient-management-during-the-covid-19-pandemic. Accessed 27 July 2020.

9. NICE. COVID-19 rapid guideline: delivery of systemic anticancer treatments. 2020. https://www.nice.org.uk/ guidance/ng161. Accessed 28 July 2020.

10. Thomson DJ, Palma D, Guckenberger M, et al. Practice recommendations for risk-adapted head and neck cancer radiation therapy during the COVID-19 pandemic: an ASTRO-ESTRO consensus statement. Int J Radiat Oncol Biol Phys. 2020;107(4):618-27.

11. World of Meters. Italy. 2020. https://www.worldometers. info/coronavirus/country/italy/. Accessed 28 July 2020.

12. Havers FP, Reed C, Lim T, et al. Seroprevalence of antibodies to SARS-CoV-2 in 10 sites in the United States, march 23-may 12. JAMA Intern Med. 2020; https://doi.org/10. 1001 /jamainternmed.2020.4130.

13. Stringhini S, Wisniak A, Piumatti G, et al. Seroprevalence of anti-SARS-CoV-2 IgG antibodies in Geneva, Switzerland (SEROCoV-POP): a population-based study. Lancet. 2020; https://doi.org/10.1016/S0140-6736(20)31304-0.

14. Fong D, Rauch S, Petter C, et al. Infection rate and clinical management of cancer patients during the COVID19 pandemic: experience from a tertiary care hospital in northern Italy. ESMOOpen. 2020;5(3):e810.

15. Bryan A, Pepper G, Wener MH, et al. Performance characteristics of the Abbott architect SARS-coV-2 IgG assay and seroprevalence in Boise, Idaho. J Clin Microbiol. 2020; https://doi.org/10.1128/JCM.00941-20.

16. Wang D, Hu B, Hu C, et al. Clinical characteristics of 138 hospitalized patients with 2019 novel coronavirus-infected pneumonia in Wuhan, China. JAMA. 2020;323(11):1061-9.

17. Palmieri L, Andrianou X, Barbariol P, et al. Characteristics of SARS-CoV-2 patients dying in Italy. 2020. https://www. epicentro.iss.it/en/coronavirus/sars-cov-2-analysis- ofdeaths. Accessed 28 July 2020.

18. Omarini C, Maur M, Luppi G, etal. Cancer treatment during the coronavirus disease 2019 pandemic: do not postpone, do it! Eur J Cancer. 2020;133:29-32.

19. Tao L, Guang Z, Huangheng T, et al. Low prevalence of IgG antibodies to SARS-CoV-2 in cancer patients with COVID19. Int JCancer. 2020; https://doi.org/10.1002/ijc.33148.

20. Woo MS, Steins D, Häußler V, et al. Control of SARS$\mathrm{CoV}-2$ infection in rituximab-treated neuroimmunological patients. J Neurol. 2020; https://doi.org/10.1007/s00415020-10046-8.

21. Meca-Lallana V, Aguirre C, del Río B, et al. COVID-19 in 7 multiple sclerosis patients in treatment with ANTI-CD20 therapies. Mult Scler Relat Disord. 2020; https://doi.org/ 10.1016/j.msard.2020.102306.

22. Fallet B, Kyburz D, Walker UA. Mild course of COVID-19 and spontaneous virus clearance in a patient with depleted peripheral blood B cells due to rituximab treatment. Arthritis Rheumatol. 2020; https://doi.org/10.1002/art.41380.

23. XuX, Sun J, NieS, et al. Seroprevalence of immunoglobulin $\mathrm{M}$ and $\mathrm{G}$ antibodies against SARS-CoV-2 in China. Nat Med. 2020; https://doi.org/10.1038/s41591-020-0949-6.

24. Lahner E, Dilaghi E, Prestigiacomo C, et al. Prevalence of Sars-Cov-2 infection in health workers (HWs) and diagnostic test performance: the experience of a teaching hospital in central Italy. Int J Environ Res Public Health. 2020;17(12):4417.

Publisher's Note Springer Nature remains neutral with regard to jurisdictional claims in published maps and institutional affiliations. 